\title{
BMJ Global Health Towards universal health coverage: can national health research systems deliver contextualised evidence to guide progress in Africa?
}

\author{
Juliet Nabyonga-Orem (D) , ${ }^{1}$ Joseph Okeibunor (D) ${ }^{2,3}$
}

\begin{abstract}
To cite: Nabyonga-Orem J, Okeibunor J. Towards universal health coverage: can national health research systems deliver contextualised evidence to guide progress in Africa?BMJ Global Health 2019;4:e001910. doi:10.1136/ bmjgh-2019-001910
\end{abstract}

Received 12 August 2019 Revised 18 September 2019 Accepted 19 September 2019

Check for updates

(C) Author(s) (or their employer(s)) 2019. Re-use permitted under CC BY-NC. No commercial re-use. See rights and permissions. Published by BMJ.

${ }^{1}$ World Health Organization, Inter-Country Support Team for Eastern \& Southern Africa; Health systems and services cluster, Causeway, Harare, Zimbabwe

${ }^{2}$ Health Systems and Services Cluster, World Health Organization Regional Office for Africa, Brazzaville, Congo ${ }^{3}$ Department of Sociology/ Anthropology, University of Nigeria, Nsukka, Nigeria

Correspondence to Dr Juliet Nabyonga-Orem; nabyongaj@who.int

\section{BACKGROUND}

As the global movement towards universal health coverage (UHC) gains momentum, countries in the WHO African Region will need to overcome several design and technical challenges within their health systems to achieve set targets. UHC is defined as ensuring that all people have access to needed health services of sufficient quality to be effective, while ensuring that the use of these services does not expose the user to financial hardship. ${ }^{1}$ The definition embodies several dimensions including ensuring that good quality services are available and accessible, the whole population is reached with the services they need, and no one faces financial hardships in seeking care.

Health systems must be strong to ensure attainment of the aspirations in the different dimensions. Health systems strengthening, and reforms are very challenging-both in terms of designing policies and programmes and effectively implementing them to achieve the desired impact. There is often a knowledge gap between 'how to' implement health systems changes and the technical assistance provided. Research evidence can provide guidance on how to effectively design and implement systems changes and reforms.

A recent study shows limited progress in Africa towards achieving the Sustainable Development Goals (SDGs) targets. ${ }^{2}$ Eight of the 10 least performing countries are in the WHO African Region. ${ }^{2}$ To make progress in achieving the SDGs as well as UHC, innovative approaches must be employed. Within the WHO African Region, several challenges persist among which are weak health systems, ${ }^{3}$ low investment in health, ${ }^{4}$ poor health seeking behaviour and, cultural, social and financial barriers to accessing care. ${ }^{56}$ There are also concerns about the appropriateness

\section{Summary box}

- There is progress in strengthening the national health research systems (NHRS) in the WHO African region, but persistent challenges include low government financing for health research, weak research coordination and enforcement of research laws and regulations, inadequate research infrastructure and lengthy ethical clearance processes.

- There are regional and global opportunities that can be leveraged by African countries to strengthen their NHRS, but realising the full benefit calls for action at county level with reference to setting a clear strategic direction and creating an enabling environment.

- Subregional/regional approaches to regulation of research, enhancing research capacity through sharing resources and expertise, sharing evidence or best practices in the form of an African Forum on Health Research, may offer additional benefit and stimulate the growth of an evidence-informed decision-making culture that is guided by locally generated solutions.

of service delivery models and whether they are responsive to peoples' needs. ${ }^{7}$

Several service delivery models have been advanced; for example, comprehensive, integrated model of care $^{8}$ and people and person centred integrated care for all. ${ }^{9}$ The implementation of these preferred models in Africa has been elusive as De Man et $a l^{10}$ point out that ...why so little of something so badly needed?... This brings to the fore the need for contextualised evidence, generation of local solutions and tailored approaches. Research for health can play a significant role in this regard-to discover affordable service delivery models and identify ways to optimise the use of existing tools or solutions to address health systems challenges, including those that militated against the achievements of the Millennium development goals. 


\section{CAN NATIONAL HEALTH RESEARCH SYSTEMS DELIVER?}

The endorsement of the Research for Health: a Strategy for The African Region 2016-2025 ${ }^{11}$, by ministers of health in the WHO African region in 2015 ushered in a renewed focus on strengthening national health research systems (NHRS). The 2018 assessment of progress in implementation of the research strategy in the 47 member states, showed improvement over an earlier 2014 assessment in strengthening governance for research (development of policies and strategies, laws and legislations, research priority lists and strengthening ethical review), developing and sustaining research resources (universities with training programme that have included research, presence of national research institutions) and, producing and using research (establishing knowledge translation platforms).

Identified major challenges include low government financing for health research; weak research coordination capacity; weak enforcement of laws and regulations; inadequate research infrastructure and lengthy ethical clearance processes. ${ }^{12}$ Worse still, most research activities in the WHO Africa region are driven by external partners, with low prospects of local ownership and sustainability. The research arena is characterised by a multiplicity of actors, dispersed efforts and unclear results in relation to impact on priority health problems. ${ }^{13}$ Consequently, Africa's percentage share of global health research output is minimal; for example, Africa produced only $1.3 \%$ of the global health research publications in $2014 .{ }^{14}$

\section{EMBRACING OPPORTUNITIES}

A few major initiatives complement the aspirations of the WHO African research strategy ${ }^{11}$ and provide opportunities for maximising the benefits of health research in Africa. The recently launched Health Research and Innovation Strategy (HRIS) for Africa $2018-2030^{15}$ by the African Union (AU) seeks to "promote and increase health research and innovation for improved health and well-being of Africa's Peoples'. The objectives therein address some of the persistent challenges among which is ensuring sustainable financing, adoption of emerging technologies, strengthening research regulation and intellectual property rights to leverage benefits and building sustainable research capacity.

The long-standing investment in strengthening research ethics and building capacity for clinical trials by initiatives like the European and Developing Countries Clinical Trials Partnership, NIH Fogarty, Africa Medicines Harmonisation Initiative, Africa Vaccines regulators Forum and others ${ }^{16}$ offer additional opportunities. Tackling infections to benefit Africa (TIBA), which is an African led wide-ranging multidisciplinary research programme, seeks to empower African Scientists to effectively and sustainably tackle neglected tropical diseases. ${ }^{17}$ TIBA is currently running research programmes in nine countries.
Other opportunities for responsive research in Africa include the Evidence-Informed-Policy Network (EVIPNet) Africa, Cochrane Africa Network and WHO collaborating centres. The mission of EVIPNet Africa is to promote a network of partnerships at national and regional levels among health system policymakers, civil society, healthcare workers, healthcare managers, researchers, funders and others; to strengthen health systems and improve health outcomes through regular access to assessment, adaptation and use of context-specific research evidence. ${ }^{18}$ Cochrane is a global independent network of healthcare practitioners, researchers, patient advocates and others, responding to the challenge of making the vast amounts of evidence generated through research useful for informing decisions about health. Cochrane collects and summarises the best health evidence from research to help health professionals to make informed choices about treatment.

The existence of the African Advisory Committee on Health Research and Development (AACHRD) offers another opportunity to ensure generation of evidence targeted at information gaps in African countries. The AACHRD is a multidisciplinary, multisectorial body established in 1979, to provide advice to the WHO African region on matters of research related to health development. It meets annually and has a consultative role with regards to shaping the research agenda and stimulating the generation, translation and dissemination of valuable knowledge in the African region. The 15-20 committee members serve in their personal capacity and represent a board range of disciplines encompassing many aspects of research for health and development.

WHO collaborating centres, which are institutions appointed by WHO, support the organisation's programmes at any level from country to the headquarters. Such centres, located in Africa, could play a role in the systematic generation and use of evidence to overcome health systems challenges in the region. However, of the over $700 \mathrm{WHO}$ collaborating centres worldwide, only $25(3 \%)$ are in the WHO African Region, and only a few of them currently focus on health systems core functions. ${ }^{19}$ It is perhaps time for WHO to revisit the terms of reference of existing collaborating centres and consider establishing new ones to address the health system priorities that are currently not addressed.

\section{MOVING FORWARD}

Leveraging available opportunities to strengthen NHRS and generate contextualised evidence to advance UHC will require actions at national, subregional and regional level. The low funding for health research has been attributed to lack of political commitment and the recently launched HRIS by the AU will hopefully mobilise the necessary political leverage. The AU has committed to develop a score card to regularly monitor the implementation of the HRIS. This will complement the WHO Africa Region biennial assessment of the status of NHRS, 
results of which are presented to ministers of health from member states during regional committee meetings.

Subregion action could be undertaken within the economic communities, Southern Africa Development Cooperation, the East African Community and the Economic Community of West African States focussing on standardising laws and legislations for research and embracing a regional approach to regulation of research, building research capacity at a subregional level to share resources and expertise and sharing research results for uptake.

Region-wide mechanisms for sharing relevant evidence or best practices may take the form of an African Forum on Health Research, to play a leadership role in stimulating the growth of an evidence-informed decision-making culture that is guided by local priorities and locally generated research and innovation. National level action could focus on implementation of the objectives of the WHO African region research strategy and the HRIS while leveraging global and continental opportunities.

Contributors $\mathrm{JN}-0$ led the drafting of the commentary. J0 reviewed the commentary and contributed to its finalisation. All authors reviewed and approved the commentary paper.

Funding WHO Africa Regional office.

Competing interests None declared.

Patient consent for publication Not required.

Provenance and peer review Not commissioned; internally peer reviewed.

Data availability statement There are no data in this work.

Open access This is an open access article distributed in accordance with the Creative Commons Attribution Non Commercial (CC BY-NC 4.0) license, which permits others to distribute, remix, adapt, build upon this work non-commercially, and license their derivative works on different terms, provided the original work is properly cited, appropriate credit is given, any changes made indicated, and the use is non-commercial. See: http://creativecommons.org/licenses/by-nc/4.0/.

ORCID iDs

Juliet Nabyonga-Orem http://orcid.org/0000-0002-1061-8678

Joseph Okeibunor http://orcid.org/0000-0002-6696-8503

\section{REFERENCES}

1 World Health Organisation. World health report. Geneva Switzerland, 2010.
2 Lim SS, Allen K, Bhutta ZA, et al. Measuring the health-related sustainable development goals in 188 countries: a baseline analysis from the global burden of disease study 2015. The Lancet 2016;388:1813-50.

3 Kieny MP, Bekedam H, Dovlo D, et al. Strengthening health systems for universal health coverage and sustainable development. Bull World Health Organ 2017:95:537-9.

4 World Health Organization. New perspectives on global health spending for universal health coverage (NO. WHO/HIS/HGF/ HFWorkingPaper/17.10. Geneva Switzerland: World Health Organization, 2017.

5 Yorlets RR, Iverson KR, Leslie HH, et al. Latent class analysis of the social determinants of health-seeking behaviour for delivery among pregnant women in Malawi. BMJ Glob Health 2019;4:e000930.

6 Gyasi RM, Adam AM, Phillips DR, et al. Financial inclusion, HealthSeeking behavior, and health outcomes among older adults in Ghana. Res Aging 2019;41:794-820.

7 Adjetey V, Obiri-Yeboah D, Dornoo B. Differentiated service delivery: a qualitative study of people living with HIV and accessing care in a tertiary facility in Ghana. BMC Health Serv Res 2019;19:95.

8 Flannery F, Adams D, O'Connor N. A community mental health service delivery model: integrating the evidence base within existing clinical models. Australas Psychiatry 2011:19:49-55.

9 Cloninger CR, Salvador-Carulla L, Kirmayer LJ, et al. A time for action on health inequities: foundations of the 2014 Geneva Declaration on Person- and People-centered integrated health care for all. Int J Pers Cent Med 2014;4:69.

10 De Man J, MAc NS, Waweru E, et al. Patient-Centered care and people-centered health systems in sub-Saharan Africa: why so little of something so badly needed? Int J Pers Cent Med 2016;6:162-73.

11 WHO Regional Office for Africa. Research for Health: A Strategy for the African Region, 2016-2025. In: Who regional Committee for Africa resolution AFR/RC65/R2. Brazzaville Congo: WHO Regional Office for Africa, 2015.

12 Rusakaniko S, Makanga M, Ota MO, et al. Strengthening national health research systems in the WHO African Region - progress towards universal health coverage. Global Health 2019;15:50.

13 Birbeck GL, Wiysonge CS, Mills EJ, et al. Global health: the importance of evidence-based medicine. BMC Med 2013;11:223

14 Uthman OA, Wiysonge CS, Ota MO, et al. Increasing the value of health research in the WHO African Region beyond 2015--reflecting on the past, celebrating the present and building the future: a bibliometric analysis. BMJ Open 2015;5:e006340.

15 African Union. Health research and innovation strategy for Africa 2018 - 2030. Addis Ethiopia 2019.

16 Whitaker C, Singh M, Fakier N, et al. The development of bioethics in Africa: the role of the European and Developing Countries Clinical Trials Partnership. Highlights EDCTP's activities to strengthen bioethics capacity in Africa. June 2018, the Central European Journal of Medicine (one of series of articles on 'Medical Ethics in the 70 Years after the Nuremberg Code, 1947 to the Present'). Cent Eur J Med 2018

17 The University Of Edinburgh. NIHR global health research unit tackling infections to benefit Africa.

18 Lavis JN, Panisset U. EVIPNet Africa's first series of policy briefs to support evidence-informed policymaking. Int J Technol Assess Health Care 2010;26:229-32.

19 World Health Organization. Who collaborating centres. Geneva Switzerland: World Health Organization, 2019. www.who.int/ collaboratingcentres/en 